\title{
Em busca de uma instituição para a pessoa idosa morar: motivos apontados por familiares*
}

LOOKING FORANURSING HOME FORAN ELDERLY PERSON: REASONSAPPOINTED BY RELATIVES

BUSCANDO UNA INSTITUCIÓN PARA QUE VIVA ELANCIANO: LOS MOTIVOS DE LOS FAMILIARES

\author{
Nara Marilene O. Girardon Perlini ${ }^{1}$, Marinês Tambara Leite ${ }^{2}$, Ana Carolina Furini ${ }^{3}$
}

\begin{abstract}
RESUMO
Com o objetivo de conhecer as situações que motivam famílias a asilar seu familiar idoso, desenvolvemos estudo de abordagem metodológica qualitativa, da qual participaram seis familiares responsáveis por idosos asilados. A coleta das informações ocorreu por meio de entrevista aberta. A análise confluiu para duas categorias denominadas: o asilamento como forma de atender às necessidades do idoso e a busca pelo melhor local para o idoso morar e manter o vínculo com a família. Viver o processo de asilamento de um familiar idoso constitui-se num período de transição em que diferentes fatores são levados em consideração e contribuem na decisão de asilar o velho. Quando há esta deliberação, a família vai à busca do melhor local para $\mathrm{o}$ idoso morar em termos de estrutura física, cuidados e convívio social com iguais e outras pessoas, pois entendem que por meio de visitas podem manter vínculos familiares e afetivos.
\end{abstract}

\begin{abstract}
This study, conceived in order to try to understand the situations that motivate families to place elderly relatives in nursing homes, used a methodological qualitative approach. Data collection was conducted through open interviews. The analysis of the answers resulted in two categories: the placement in a nursing home as a way to meet the elder person's needs; and the search for the best place for the elder to live and keep the bond with the family. Living through the process of placing an elder relative in a nursing home constituted a transition period in which different factors were taken into account and contributed for the decision. When this decision is taken, the family looks for the best place in terms of physical structure, care and social living, with equals and with other people, because it is believed that through visits family and affective bonds can be kept.
\end{abstract}

\section{KEY WORDS}

Aged.

Family.

Institutionalization.

Geriatric nursing.

\section{RESUMEN}

Con el fin de comprender las situaciones que motivan a las familias a asilar un miembro anciano de su familia se realizó un estudio de abordaje metodológica cualitativa, de la cual participaron seis familiares responsables por ancianos recluidos. La colecta de las informaciones ocurrió por medio de entrevistas abiertas. El análisis condujo a dos categorías denominadas: El aislamiento como forma de atender a las necesidades del anciano y Buscar el mejor lugar para que el anciano viva y mantenga el vínculo con la familia. Vivir el proceso de asilar un familiar anciano es un periodo de transición en que diferentes factores son considerados y contribuyen para esta decisión. Cuando hay esta deliberación, la familia busca la mejor residencia para el viejo en términos de estructura física, cuidados y convivencia social con sus congéneres y otras personas. Entienden que por medio de visitas podrán mantener vínculos familiares y afectivos.

\footnotetext{
* Extraída da pesquisa financiada pelo $\mathrm{Pibic/}$ Unijuí. Integra o Programa de Pesquisa Políticas Públicas, Planejamento e Gestão em Saúde do Depto. de Ciências da Saúde da Universidade Regional do Noroeste do Estado do Rio Grande do Sul.

1 Enfermeira. Mestre em Enfermagem pela EEUSP. Docente do DCSa-Unijuí. nara.girardon@ unijui.tche.br

2 Enfermeira. Mestre em Enfermagem pela EERP. Doutoranda em Gerontologia PUC-RS. Docente do DCSa-Unijuí. marinesl@ unijui.tche.br

3 Graduanda do Curso de Enfermagem da Unijuí. Bolsista PibicUnijui, período 2004 2005.

anafurini@bol.com.br
}

\author{
DESCRITORES \\ Família. \\ Institucionalização. \\ Enfermagem geriátrica.
}




\section{INTRODUÇÃO}

A crescente necessidade de institucionalização de idosos tem chamado a atenção da população em geral e levado alguns segmentos da sociedade a se preocuparem com as condições em que se encontra o contingente populacional residente nestes espaços. Freqüentemente surgem notícias veiculando informações, com abordagens que destacam aspectos positivos acerca das potencialidades envolvendo $o$ viver em locais que abrigam pessoas idosas. Também são ressaltados aspectos negativos, como a existência de maustratos, estrutura física deficitária e falta de recursos humanos capacitados para atuar com idosos que residem em ancionatos, particularmente naqueles de natureza pública, os quais dão a entender que esta deve ser uma preocupação constante dos profissionais que estão envolvidos com a problemática, assim como dos familiares das pessoas idosas que passaram a residir em uma instituição asilar.

No Brasil, dados demográficos demonstram que a população encontra-se em um rápido processo de envelhecimento e, em conseqüência, a cada ano há um acréscimo significativo no número de anciões em nossa sociedade. Esta situação, aliada a modificações na estrutura familiar e à dinâmica da sociedade, em que há, cada vez mais, a inserção do maior número possível de integrantes da família no mercado de trabalho, em especial a mulher, expõe a pessoa idosa ao risco de vir a ser institucionalizada.

$\mathrm{O}$ atendimento ao idoso deve ser, preferencialmente, na modalidade não asilar, porém naquelas situações em que os idosos não possuem condições que garantam sua própria sobrevivência é responsabilidade do Estado manter instituições asilares para abrigar estas pessoas. Além disso, a Política Nacional do Idoso norteia ações que visam ao desenvolvimento dos idosos, garantindo autonomia e independência no atendimento de suas necessidades específicas - auto-suficiência, saúde, moradia e segurança - conforme preconiza a Lei $n^{\circ} 8.842 / 94$. Essa política prevê, ainda, que a família, a sociedade e o Estado devem assegurar ao idoso todos os direitos de cidadania, garantindo sua participação na comunidade, defendendo sua dignidade, bem-estar e o direito à vida ${ }^{(1)}$.

Quando uma família procura um asilo como local para seu familiar idoso morar busca, entre outras demandas, um ambiente que ofereça cuidados, companhia, além de ser um espaço de convivência e socialização entre os moradores.

Culturalmente, em nossa sociedade, é esperado que na velhice dos pais, os filhos, mais diretamente, ou os demais integrantes da família, assumam a responsabilidade pelos seus cuidados, provendo-os material e afetivamente de acordo com as condições e as necessidades de cada caso.

A família, seja aquela definida como nuclear, formada por pais e filhos, ou a expandida, que inclui as pessoas que são consideradas como membros de uma mesma família, independente de laços consangüíneos ou parentais, constituise na fonte primária de auxílio e cuidados aos seus integrantes, desde o nascimento até a morte.

Os significados, os valores e as crenças desenvolvidos em cada família são construídos no processo familiar, ou seja, no seio da própria família, nas experiências vividas e compartilhadas de geração em geração e, também, por influência do meio em que vivem, sendo que neste se constituem, por outro lado, em agentes que também influenciam. Nesse sentido, o cuidado familiar acontece de forma "inter e intrageracional", ou seja, os pais cuidam dos filhos, os mais velhos cuidam dos mais novos em certos momentos e serão por estes assistidos em outros. O cuidado intergeracional envolve pais, avós e netos e o intrageracional, esposos, irmãos, primos $^{(2-3)}$.

Como cuidadores primários ou responsáveis pela assistência a idosos dependentes ou não, estudos realizados na cidade de Ijuí convergem aos encontrados em outras localidades do país, sendo que estes são assumidos prioritariamente pelas mulheres, principalmente esposas, filhas, noras ou netas, ou irmãs, sobrinhas e cunhadas ${ }^{(4-7)}$.

Considerando a família como fonte de cuidado, optar pela institucionalização de um de seus membros neste caso, o idoso, a decisão, a priori, reveste-se de uma intenção que visa proporcionar melhores condições de vida, de cuidado e de conforto, mais qualificadas que aquelas que a família pode oferecer.

Em determinadas situações ou períodos, a capacidade da família para o cuidado pode estar comprometida ou fragilizada e, nestas condições, o idoso pode constituir-se num entrave à autonomia dos familiares, seja pelas demandas do cotidiano, que não lhes possibilita conciliar cuidado e atividades de trabalho e do lar, ou pela impossibilidade de dentre os familiares encontrar um ou mais membros que se disponibilizem e se responsabilizem pelo cuidado do idoso. A institucionalização, então, é uma das soluções encontradas para o problema.

Deve-se considerar, entretanto, que o estereótipo de que os asilamentos ocorrem em virtude de filhos que querem "se livrar" dos pais idosos e dependentes ou não e que não se adaptam aos "tempos modernos" é uma realidade que prevalece na concepção de muitas pessoas.

A família é um sistema de saúde para seus membros e exerce o papel de cuidadora e supervisora, tanto em situações de saúde quanto de doença, tomando decisões relativas aos caminhos a seguir, acompanhando, avaliando e pedindo ajuda aos seus significantes e/ou aos profissionais. Além disso, outros estudos apontam para situações de não cuidado por parte da família para com seus integrantes, sendo a violência uma realidade que não pode ser negada ${ }^{(2)}$. 
Tendo em conta a importância do papel da família no cuidado de seus membros, cabe aos profissionais aprofundar conhecimentos com o objetivo de conhecer as situações que motivam famílias residentes no município de Ijuí/RS a asilar seu familiar idoso.

\section{MÉTODO}

Considerando a natureza da investigação, esta possui características metodológicas de um estudo de abordagem qualitativa, o qual busca apreender o significado, valores e crenças que os indivíduos possuem sobre determinado fenômeno ${ }^{(8)}$. Assim, a fala dos familiares constitui-se na fonte das informações que possibilitam conhecer, ao menos em parte, o processo de institucionalização de seus familiares idosos.

No município de Ijuí está localizado o Serviço de Amparo e Bem Estar à Velhice (SABEVE), instituição na qual residem os idosos cujas famílias constituem-se fonte de informações para o desenvolvimento deste estudo. Neste local moram 35 idosos, dos quais 19 possuem familiares residindo no município e os demais têm seus familiares morando em municípios circunvizinhos ou em outros Estados da Federação.

Os participantes da pesquisa são seis pessoas, que constam nos arquivos da instituição como responsáveis pelos idosos, possuindo o seguinte grau de parentesco consangüíneo: um filho, duas filhas, um irmão e uma sobrinha. Há, ainda, um sobrinho-neto, com vínculo por afinidade. O número de entrevistados decorreu da utilização da técnica de saturação ou recorrência dos dados, isto é, no momento em que a busca de novos sujeitos não acrescentou mais nenhum dado novo à investigação ${ }^{(8-9)}$.

A coleta das informações ocorreu por meio de entrevista aberta, gravada e transcrita na íntegra, com a seguinte questão balizadora: Fale como foi para sua família a ida de seu familiar para o asilo.

A partir dos dados relativos a endereço e telefone para contato dos familiares de idosos que residem na Sabeve e tendo como critério de inclusão a possibilidade de acesso aos mesmos, manteve-se contato pessoal ou telefônico com estes, aleatoriamente, com a finalidade de informar sobre a realização da pesquisa, seu objetivo, convidá-los participar e, em caso afirmativo, agendava-se visita domiciliar, visando à realização da entrevista. Todos os indivíduos contatados concordaram em colaborar e assinaram o Termo de Consentimento Livre e Esclarecido (TCLE).

$\mathrm{Na}$ análise dos dados seguiram-se os seguintes passos: ordenação do material e leitura flutuante das informações; leitura exaustiva e categorização em temas e análise final $^{(8)}$. Dessa forma, construíram-se dois temas: asilando como forma de atender às necessidades do idoso e buscando o melhor local para o ancião morar e manter o vínculo com a família.

Salienta-se que os preceitos estabelecidos pela Resolução 196/96 do Conselho Nacional de Saúde do Ministério da Saúde, que regulamenta os cuidados éticos da pesquisa com seres humanos foram fielmente observados ${ }^{(10)}$, tendo o projeto sido aprovado pelo Comitê de Ética em Pesquisa da Unijuí, mediante Parecer Consubstanciado nº 34/2004.

\section{APRESENTAÇÃOE DISCUSSÃO DOS RESULTADOS}

A análise das informações conformou duas categorias, quais sejam: a primeira aborda a atenção requerida pela pessoa idosa, entendida como o atendimento às necessidades do ponto de vista econômico, social e de saúde; a segunda discorre acerca das concepções que a família tem de asilo como o melhor local possível para o idoso viver e a manutenção dos laços familiares.

\section{$O$ asilamento como forma de atender às necessidades do idoso}

As questões relativas à velhice em sua fase mais avançada preocupam os familiares, pois entendem que a pessoa idosa pode já não mais possuir condições de viver só, no espaço doméstico, uma vez que passa a apresentar limitações para realizar as atividades da vida diária e, muitas vezes, estar impossibilitada de gerenciar seu domicílio, como prover alimentação, pagar água, luz, ir ao banco, entre outros. Estes motivos podem se apresentar de forma isolada ou estarem associados entre si.

As limitações, relativas ou absolutas, colocam o idoso em uma relação de dependência de alguém que possa auxiliá-lo na realização dos afazeres do cotidiano. Freqüentemente quem assume essa tarefa é um familiar, pela proximidade afetiva e/ou geográfica. Assim, a família constitui-se no ponto de referência para os cuidados diretos à pessoa idosa e, ainda, na administração do espaço domiciliar em que o idoso reside.

Nos casos em que o idoso não possui descendentes diretos, contudo, há uma maior probabilidade de que o asilamento seja uma conseqüência quase natural, uma vez que, comumente, são os irmãos ou sobrinhos que passam a assumir a responsabilidade pelo cuidado. Vale lembrar que esta situação torna-se mais evidente quando ocorre a impossibilidade ou ausência (morte) de um dos cônjuges, em especial naquelas situações em que os idosos mantinham laços conjugais.

Era um casal que não tiveram filhos (...). Mas aí o tio faleceu. Como a gente ia tratar a questão da tia? Com o salário que ela ganhava com a pensão, não dava para manter casa, água e luz e uma pessoa para morar junto, cuidar. O que a gente achou por bem fazer foi visualizar um espaço. Um espaço dela se sustentar, alguém para amparar no sentido de enfermeira, alguma coisa desse tipo (E4 - sobrinho). 
Ela morava com meu pai e minha mãe, ela é solteira. Minha avó faleceu e ela acabou morando com a minha mãe... Então a minha mãe faleceu e ela continuou morando na casa, com meu pai. Meu pai acabou falecendo (...). Meu irmão é falecido e minha cunhada mora em Curitiba, então só tava eu sozinha pra cuidar dela (E5 - sobrinha).

A idéia de que o idoso desprovido de família nuclear possui maior probabilidade de asilamento está em consonância com o que prevê a Política Nacional de Atenção ao Idoso, expressa na Lei $\mathrm{n}^{\circ}$ 8.842/94 e regulamentada pelo Decreto $\mathrm{n}^{\circ} 1.948 / 96$, ao explicitar que a modalidade asilar de assistência social ao idoso "ocorre no caso da inexistência do grupo familiar, abandono e carência de recursos financeiros próprios ou da própria família" (artigo $3^{\circ}, \S$ único) ${ }^{(1)}$.

Estudo desenvolvido com a finalidade de delinear o perfil dos idosos institucionalizados no município de Caxias do $\mathrm{Sul} / \mathrm{RS}$ revela que, da amostra estudada, a maioria dos idosos ainda possui família, sendo esta representada, principalmente, por irmãos, tios e sobrinhos, seguido de filhos e netos $^{(11)}$. Somente um pequeno percentual tem companheiro. Os dados indicam, também, que o elevado percentual de idosos solteiros e viúvos demonstra que a ausência de companheiro é um fator determinante para o asilamento. Diante desse panorama as pesquisadoras concluem que a não constituição de uma família nuclear leva o idoso ao desamparo no limiar do envelhecimento e que a presença do cônjuge, comumente, garante a permanência do velho no domicílio.

Outro motivo evidenciado na realidade que ora estudamos diz respeito à impossibilidade dos filhos em conciliar as atividades laborais e pessoais com o cuidado à pessoa idosa no ambiente doméstico, principalmente quando esta se apresenta dependente. Enfatiza-se que, em um primeiro momento, há movimento dos familiares em garantir a permanência e o atendimento das necessidades do idoso no espaço familiar, dando a entender que os filhos assumem para si a tarefa de amparar seu pai ou sua mãe quando estes já não podem assumir o controle das atividades do cotidiano e de si mesmos.

\footnotetext{
É somente eu e meu irmão e nós estávamos há sete anos com ela, cuidando dela. Chegou um ponto em que nós tínhamos tantas atividades que ela ficava mais sozinha, com empregadas, do que conosco. E no fim não tava mais sendo bom pra ela e nem pra nós. Tava mais como um peso, aquilo assim... mais como um tipo de estresse do que outra coisa (E6 - filha).

O meu pai está no asilo, única e exclusivamente, porque não tem quem cuide dele. Eu me vi aos tombos, como diz o outro, tentando achar alguém para cuidar dele. Passei três semanas tentando dar conta de trabalhar e cuidar do pai ao mesmo tempo. Se eu tivesse condições, fosse aposentada, cuidaria dele em casa (E3 - filha).
}

As dificuldades de relacionamento com os demais membros da família também são fatores que contribuem para que o idoso seja enviado para uma instituição de longa perma- nência. Depreende-se das falas que os conflitos acontecem mais em função da postura intransigente e autoritária, por parte da pessoa idosa, do que pela falta de flexibilidade dos familiares mais jovens. Isto talvez seja em virtude da característica que as pessoas velhas apresentam, ou seja, de resistirem a possíveis mudanças e terem a concepção de que as suas atitudes devam ser prevalentes e acatadas por quem com elas convivem.

Então ficou um pouco difícil, sempre bastante autoritária, então eu não podia ter ela aqui na minha casa. Por isso... aí ela foi pra lá (...). Ela sempre tem que ter a última palavra. Então, pra ter ela aqui em casa, com o meu marido, não dá. E o meu marido disse assim, "se ela entrar aqui eu saio pela outra porta". Mas podia estar aqui, se ela não fosse assim tão... (E5 - sobrinha).

Mas a mãe tem vício, ela fuma bastante. A maior parte de seus filhos são alérgicos ou tem problema de peito. Ela ficou, ainda, morando com os filhos. Depois, na insistência dos filhos sobre o estado que ela deixasse de fumar, ela não mais aceitou isso e começou a se negar. Pra viver sossegadamente (...) ela optou em buscar um lugar pra ela, em que nenhum filho a incomodasse, principalmente nessa questão do cigarro. A tônica maior é que os filhos "incomodam", mas na realidade só querem o bem dela, preservação e manutenção da saúde dela (E2 - filho).

Dentre as considerações do estudo realizado, aparece a exposição de que a história de conflitos sufocados ou de relações interpessoais mal-resolvidas no decorrer da vida impelem a que, em algum momento, aconteça o chamado "acerto de contas", podendo resultar no asilamento da pessoa idosa $a^{(11)}$.

Muitas vezes a opção por residir em uma instituição de longa permanência parte do próprio idoso, ou seja, do desejo da pessoa em procurar um local no qual encontre atenção, conforto e, especialmente, atendimento às suas necessidades básicas. Nesse contexto, a situação econômica é um ponto preponderante para a decisão de morar em um residencial para idosos, além da possibilidade de não precisar realizar as tarefas domésticas, como se percebe na fala de um dos entrevistados:

Ela ganha razoavelmente bem, ela pode pagar sua estadia e, ainda, assim sobra um dinheirinho pra comprar os seus vícios. E lá ela não gosta de fazer nada, ela gosta de tudo nas mãos. Ela foi uma senhora que teve um bom nível de vida quando nova e de velha também. E lá ela tem todo o serviço a seu dispor. Ela paga, mas ganha roupa limpa, roupa passada, roupa costurada, seu apartamento (E2 - filho).

O adoecimento do idoso que resulte em impossibilidade de realizar as atividades da vida diária e/ou instrumental, e a necessidade de cuidados especiais, como no caso de dependência absoluta, em que há exigência de alguém para prestar o cuidado contínuo e que a família não tenha pos-
Em busca de uma instituição para a pessoa idosa morar: motivos apontados por familiares Perlini NMOG, Leite MT, Furini AC. 
sibilidade de provê-lo, é outro motivo apontado pelos entrevistados para a internação em uma instituição asilar. O adoecimento e a conseqüente dependência não estão exclusivamente relacionados às questões orgânicas, mas também se referem aos aspectos da cognição, como nas demências em geral.

\begin{abstract}
Ela era sozinha e ficou doente. Uma pessoa doente não é possível ficar sozinha (...). Por causa da demência, ela se esquece dos remédios. Então acelerou a doença. Quando ela estava bem, se esquecia e quando ela se atacava, porque ela tem Parkinson, ela tomava um atrás do outro. Ela marcava hora no médico e não ia, ia no outro dia (...). É o motivo mais certo que nós não podemos ficar com ela, nem aqui nem no meu irmão, nós já tentamos, mas não deu porque quando ela quer o remédio, ela quer e pronto (E1 - irmão).
\end{abstract}

As patologias de caráter orgânico que resultam em incapacidades, tanto motoras como cognitivas, também se constituem em um importante motivo para que a família busque uma instituição que ofereça, além de moradia, recursos humanos capacitados para atender e prestar os cuidados necessários ao idoso. Isso se evidencia, claramente, nas situações em que há dependência total.

\section{Tem que dar atenção o dia todo, ele não pode ficar sozinho. Era muito difícil de dar conta. Tinha que dar banho, limpar todo dia... ele teve três derrames, e quase não caminhava, mas ele conseguia caminhar vagarento, tinha uma perna que ajudava ele, só que ele caiu e quebrou a perna direita, aí ele botou uma prótese e agora ele não caminha mais. Ele só ficava na cama. Agora ele ta indo na cadeira de rodas. Tiram ele, botam na cama, as duas horas ele sai da cama vai pra cadeira de rodas (E3 - filha).}

Diversos autores ressaltam que o cuidado a idosos tem sido geralmente uma atribuição feminina, porém com a entrada cada vez mais acentuada da mulher no mercado de trabalho e as mudanças na estrutura familiar, as situações de cuidado, que ficavam naturalmente a cargo da mulher, tornaram-se objeto de tensão e conflitos. Cuidar dos familiares idosos é mais um dos papéis que são atribuídos à mulher na esfera do lar. A realidade é que as famílias não encontram condições objetivas e subjetivas necessárias para cuidar de seus velhos no âmbito estritamente privado $^{(12-13)}$.

No presente estudo há, também, a manifestação de que nas situações de dependência relativa o asilamento proporciona a garantia de que o cuidado se dará de forma efetiva e que possíveis alterações sejam precocemente identificadas e solucionadas.

Todo mundo trabalha, então nós trouxemos pra cá, mas mediante a doença dela nós, também, não tivemos como manter ela aqui. Então, ela foi pra lá. Nós achamos o único bem de colocar ela lá, porque lá tem enfermeira, tem doutor, um ambiente muito bom. Nós não teríamos condições de dar o que eles tão dando lá. Assistência inclusive com pessoas estagiárias que vão lá toda semana (E1 - irmão).
A dependência do idoso e a necessidade de os familiares manterem-se no mercado de trabalho, aliada à dificuldade em encontrar e manter um cuidador formal, que responda pelo atendimento das demandas oriundas da pessoa idosa doente, constitui-se em outro motivo para o encaminhamento desta a uma instituição de longa permanência. Normalmente a família busca, em um primeiro momento, alguém que já tenha conhecimentos e habilidade para prestar os cuidados necessários. Quando não o consegue, passa a contratar pessoas que se disponham a realizar esta incumbência. Contudo, quando todas as possibilidades parecem ter sido esgotadas, a saída encontrada é o asilamento.

Vale salientar que a tarefa de garantir que o cuidado se efetive, seja contratando pessoas ou executando pessoalmente, constitui-se em atividade desgastante, árdua e, muitas vezes, conflituosa para os familiares. Por sua vez, para o idoso que está sendo cuidado, a freqüente mudança da pessoa cuidadora torna-se sofrida, estressante e conturbada. Ser cuidador de uma pessoa idosa, principalmente se for dependente, exige bom condicionamento físico, paciência e tolerância, constituindo-se em uma atribuição difícil de ser cumprida. Para esse tipo de trabalho, que é extenuante, física e psicologicamente, há dificuldade de encontrar tais cuidadores.

\begin{abstract}
Há um ano, eu peguei o pai e a mãe para morar comigo. O pai era doente e era a mãe que cuidava dele, só que a mãe faleceu. Aí eu contratei uma mulher pra cuidar do pai. Essa senhora já tinha experiência de cuidar de gente idosa e acabou saindo em função de que a mãe dela adoeceu. Aí eu arrumei uma outra pessoa, mas o pai não se acertava muito com ela. Trabalhou um mês e pouco. Ficou uma semana sem vir, disse que viria na outra e acabou ficando três semanas sem vir. Aí tem pessoas jovens que não têm experiência. Cuidar de uma pessoa idosa do jeito que ele estava era difícil (...) Tem que ter muita estrutura, boa vontade para cuidar, porque dá o que fazer. É difícil, também, porque quem é profissional, quem é enfermeiro, não aceita um salário mínimo (E3 - filha).
\end{abstract}

Os familiares participantes deste estudo apontam, com base em sua vivência, diversos motivos que contribuem para que idosos passem a residir em instituições de longa permanência. Dentre eles destaca-se que para alguns o encaminhamento ao asilo é resultado da ausência de descendentes diretos; para outros, é em virtude da impossibilidade dos filhos de conciliar trabalho e cuidar dos pais que são idosos, principalmente quando estes se encontram doentes e dependentes. Para uma parcela dos colaboradores, o motivo indicado para residir em uma instituição é por desejo do próprio idoso.

\section{A busca pelo melhor local para o idoso morar e manter o vínculo com a família}

Diante da impossibilidade de manter a pessoa idosa no domicílio, a família passa a pensar no asilamento como um recurso viável. Uma vez tomada a decisão, começa a procura pelo melhor local para que o idoso possa morar, 
ser bem atendido em suas necessidades e continuar mantendo vínculo com a família. Com o intuito de localizar tal espaço, são realizadas visitas a diferentes instituições, algumas vezes na companhia do geronte, com a finalidade de identificar aquela que poderá melhor atender as suas expectativas.

Inúmeros trabalhos que versam acerca de instituições de longa permanência ${ }^{(11,14-16)}$, porém, apontam que tais locais caracterizam-se como um locus negativo para ser um espaço de moradia para os anciões. Destacam que estes locais predispõem à segregação, pois os idosos são afastados do ambiente social e humano que sempre freqüentaram. Além disso, apresentam normatizações das atividades diárias, uniformização e disciplina que, muitas vezes, não permitem ao individuo preservar sua singularidade e seu espaço.

As funções dos asilos podem ser descritas como a de abrigar e cuidar de pessoas desamparadas e que estejam impossibilitadas de permanecer com suas famílias e comunidade. Além disso, de ser um local socialmente aprovado de segregação de seres humanos que, do ponto de vista de produtividade econômica e social, não mais contribuem ${ }^{(14)}$.

No entendimento dos colaboradores deste estudo, o melhor local é aquele que oferece conforto, tranqüilidade, segurança e supre as demandas relacionadas ao morar (ter roupa limpa, alimentação, ambiente higienizado, entre outros) e aos aspectos físicos e sociais.

Eu vi que as condições lá eram boas. Eu pensei: é o melhor lugar pro pai. Porque lá têm profissionais, têm pessoas, tem um grupo de idosos, tem assistência, tem fisioterapia... Ele está bem melhor atendido lá do que em casa, sozinho com uma pessoa (E3 - filha).

Nós achamos que ela está bem lá. Se é o ideal, não sei, mas é o melhor que a gente conseguiu (E6 - filha).

$\mathrm{Na}$ busca de um espaço, um fator que contribui na escolha do local relaciona-se à possibilidade de que o idoso possa organizar ali uma estrutura física o mais semelhante possível ao de sua casa. Isto implica na perspectiva de poder levar consigo móveis, utensílios e objetos com os quais está habituado, se identifica e que têm, muitas vezes, valor afetivo.

Ela foi bem assim, ela já sabia que tinha que ir pra lá. Daí a gente levou os móveis dela e tudo. Então, instalada ela está muito bem, até o sofá era da mãe, não era dela, mas eu disse: vou levar, e ela reclamando: não quero esse sofá, eu não quero. Agora ela só passa sentada nesse sofá. Foi uma boa, senão ela não teria onde sentar. Ela tem uma geladeira nova que a gente comprou. Ela tá bem instalada lá, só que... Ela não pode reclamar (E5 - sobrinha).

Além de se constituir em um espaço com boas condições de acomodação, os familiares buscam contemplar, também, aspectos referentes à qualificação dos profis- sionais que interagem com os idosos. Tal qualificação diz respeito à habilidade técnica, conhecimento e disposição pessoal em trabalhar com esse estrato da população. Além disso, vêem no asilamento a possibilidade de proporcionar maior convívio social do idoso com outras pessoas, o que permite um resgate da auto-estima, a valorização de si mesmo e minimiza o sentimento de solidão.

\begin{abstract}
No caso dela vai conseguir tocar a vida, no sentido da convivência, atenção, acho que ela fica bem mais cuidada ali do que sozinha. Tem o apoio da enfermagem. E o que a gente achou, uma coisa que ela não tinha, voltou a ter um pouco mais de vaidade, se pinta um pouco mais, se ajeita um pouco mais, tem mais auto-estima. Isso me chamou atenção, ela mudou bastante (E4 - sobrinho).
\end{abstract}

O convívio social, em alguns casos, se estende para além do espaço institucional. Visando atender a esta demanda a instituição disponibiliza o transporte para que os idosos que desejam e tenham condições possam participar de atividades religiosas, de lazer e de confraternização. Também há liberdade para que os familiares e o idoso possam juntos desfrutar de momentos em comum, como por exemplo, nos finais de semana, datas comemorativas e outras ocasiões especiais. Esta flexibilidade contribui para a manutenção dos laços afetivos, de responsabilidade e de compromisso entre os familiares.

\begin{abstract}
Claro que tem que pagar, mas o atendimento deles, comida, médico, enfermeira, tem enfermeira lá. O ambiente é ótimo, é um tratamento, limpeza, tudo muito bom. No caso, quando precisa trazem na igreja, volta e meia tem chá, ela vem tomar chá. Eles lotam a Kombi e ela vem junto (...). No caso, se quisermos pegar ela uma noite, pode. Só, claro, tem de ser com autorização deles. Então, a gente avisa, a gente liga, pede se ela tem condições de sair. Pego ela, trago na igreja, depois ela almoça aqui, e depois a gente leva ela de volta, porque a Kombi vem, mas vem muito cedo. Às vezes ela vem com a Kombi, outras a gente busca (E1 - irmão).
\end{abstract}

As visitas realizadas pelos familiares se revestem de demonstrações de afeto, interesse, preocupação e responsabilização, o que permite a conservação e a continuidade dos vínculos formados no decorrer da vida. O estabelecimento da freqüência das visitas é definido, a priori, de acordo com a disponibilidade de tempo e a distância geográfica de cada integrante da família.

Eu não fico mais de 15 dias sem ir lá ver ela, em hipótese alguma. Levo alguma coisa, se os filhos precisam, ou se ela precisa dos filhos... O familiar tem responsabilidade, não pode simplesmente largar lá. Mas em nenhum momento deixei de dar assistência para ela. Atenção, carinho, afeto, amor que ela precisa (E2 - filho).

No que se refere às visitas recebidas por idosos institucionalizados, o estudo indicou que a maioria destes recebia visitas dos integrantes do núcleo familiar, de parentes, de amigos ou de pessoas da comunidade. Também destaca que as 
pessoas do núcleo familiar visitavam mais freqüentemente dos que os parentes, mas as visitas diminuíam à medida que o tempo de asilamento aumentava, demonstrando que os "laços familiares se fragilizam com o passar do tempo, levando gradativamente ao esquecimento dos idosos"(17).

As informações deste estudo parecem estar em consonância com os achados das autoras supramencionadas e permitem, ainda, inferir que, por vezes, o comparecimento na instituição passa a ser vista como uma obrigação a ser cumprida pelos familiares.

Então, todas as semanas eu tenho que ir lá. Ela sempre reclama que eu vou pouco lá. Porque ela só tem a minha família, não tem mais ninguém, a cunhada ta lá em cima, não vem pra cá (E5 - irmã).

De modo geral, depreende-se que quando há a opção pelo asilamento do idoso, a família busca por um ambiente que possa se revelar melhor do que aquele no qual ele está residindo. Os familiares entendem que o asilo poderá oferecer, além de estrutura física, cuidados executados por profissionais, atendimento às suas necessidades básicas e possibilidade de convívio social com iguais e outras pessoas.

Acreditam também que por meio de visitas podem manter os vínculos familiares e afetivos e prestar os cuidados que permanecem sob sua responsabilidade, ou seja, de afeto, atenção, carinho e mesmo os de ordem financeira. Além disso, parece haver maior interação e entendimento entre o idoso e a família, uma vez que as questões que poderiam suscitar conflito, decorrentes da convivência contínua, estão ausentes ou se apresentam de forma velada ou, ainda, podem ser contornadas mais facilmente.

\section{CONCLUSÕES}

Viver o processo de asilamento de um familiar idoso constitui-se num período de transição e conflito para o grupo familiar, em que diversos fatores são considerados e contribuem na decisão de asilar o velho. Dentre esses fatores, o fato de ser uma família com reduzido número de integrantes, diminui a possibilidade de um dos familiares responsabilizar-se pelo cuidado do idoso; a ausência de condições físicas, financeiras e psicológicas para prestar o cuidado no domicílio, e o desejo do idoso em ter um espaço para morar sem perturbar seus familiares, são situações consideradas motivacionais para o asilamento.
Diante das dificuldades impostas ao cotidiano familiar e das restritas soluções encontradas para garantir o cuidado e a qualidade de vida do ancião, a família e, muitas vezes, o próprio geronte, visualizam a institucionalização como uma alternativa viável. A partir desta idéia formada, procuram pelo melhor local para o idoso morar, no qual esperam que este seja acolhido, bem atendido e que a manutenção dos vínculos afetivos básicos com a família seja mantida.

Evidencia-se, pelas manifestações dos colaboradores, que as concepções descritas na literatura em relação ao asilamento e às instituições asilares, de que estas favorecem a exclusão, que os idosos são tratados como objetos, que contam com restrito número de funcionários, nem sempre qualificados, e que as atividades sociorecreativas não são voltadas aos interesses dos idosos, diferem do anseio e das expectativas da família. O impacto e as repercussões da institucionalização à pessoa idosa, neste momento de impotência em encontrar outra alternativa, não são colocados em pauta, pois possivelmente são desconhecidos da maioria das famílias.

Outro aspecto que merece reflexão está relacionado às políticas de atenção à pessoa idosa, ao prever que a família deve propiciar ao idoso o atendimento de suas necessidades e dignidade, mas não disponibilizam recursos para fortalecê-la no sentido de viabilizar a manutenção do idoso no seio familiar.

A perspectiva de construir uma rede de apoio às famílias de idosos, a partir de serviços públicos, em que enfermeiros, assistentes sociais, técnicos de enfermagem, outros profissionais da saúde, cuidadores formais e voluntários pudessem, a exemplo de outros países, dar suporte técnico, orientação de cuidados, auxílio para resolver problemas e oferecer espaço de escuta para as famílias, poderia contribuir para a permanência do idoso em casa. Entende-se, também, que em algumas situações, o asilamento constitui-se, realmente, em uma opção possível. A enfermagem, nesse sentido, pode ter um papel significativo neste contexto, uma vez que, estando presente nos diferentes serviços de saúde, pode identificar as famílias que necessitam de apoio e, então, numa ação coletiva com os demais profissionais, dirigir esforços no sentido de ajudá-la.

Este estudo permitiu conhecer aspectos relacionados à dinâmica familiar que envolve o asilamento de idosos, conferindo visibilidade aos motivos que impulsionam estas famílias para tal decisão e que podem ser característicos de muitos outros núcleos familiares. Importante que outros estudos, em realidades sociais e culturais distintas da nossa, sejam realizados a fim de explicitar, também, a realidade vivida pelas famílias que têm seus idosos asilados. 


\section{REFERÊNCIAS}

1. Brasil. Lei n. 8.842, de 4 de janeiro de 1994. Dispõe sobre a Política Nacional do Idoso, cria o Conselho Nacional do Idoso e dá outras providências [legislação na Internet]. Brasília; 1994. [citado 2005 jul. 17]. Disponível em: http://www.cfess.org.br/ pdf/legislacao_idoso_8842.pdf

2. Elsen I. Cuidado familiar: uma proposta inicial de sistematização conceitual. In: Elsen I, Marcon SS, Santos MR, organizadores. O viver em família e sua interface com a saúde e a doença. Maringá: Eduem; 2002. p. 11-24.

3. Budó MLD. Cuidando e sendo cuidado: um modelo cultural de suporte à saúde em comunidade rural de descendentes de imigrantes italianos [dissertação]. Santa Maria: Programa de PósGraduação em Extensão Rural, Universidade Federal de Santa Maria; 1994.

4. Marzari F. Cuidar no domicílio: percepção de cuidadores familiares da área rural [monografia]. Ijuí: Curso de Graduação em Enfermagem, Universidade Regional do Noroeste do Estado do Rio Grande do Sul; 2004.

5. Catani RB, Perlini MOG. Cuidar do idoso doente no domicilio: a vez do cuidador familiar. Rev Eletrônica Enferm [periódico na Internet]. 2004[citado 2005 mar. 12];6(2):[cerca de 16 p.]. Disponível em: http://www.fen.ufg.br/revista.html

6. Perlini NMOG, Faro ACM. Cuidar de pessoa incapacitada por acidente vascular cerebral no domicílio: o fazer do cuidador familiar. Rev Esc Enferm USP. 2005;2(39):154-63.

7. Leite MT. Cuidando do idoso hospitalizado: a experiência do familiar [dissertação]. Ijuí: Universidade Regional do Noroeste do Estado do Rio Grande do Sul; 2000.

8. Minayo MCS. O desafio do conhecimento: pesquisa qualitativa em saúde. $2^{\text {a }}$ ed. São Paulo: Hucitec; 2000.
9. Víctora CG, Knauth DR, Hassen MNA. Pesquisa qualitativa em saúde: uma introdução ao tema. Porto Alegre: Tomo Editorial; 2000.

10. Conselho Nacional de Saúde. Resolução n. 196, de 10 de outubro de 1996. Diretrizes e normas regulamentadoras de pesquisas envolvendo seres humanos. Bioética. 1996;4(2 Supl):15-25

11. Herédia VBM, Cortelletti IA, Casara MB. Institucionalização do idoso: identidade e realidade. In: Cortelletti IA, Casara MB, Herédia VBM, organizadores. Idoso asilado: um estudo gerontológico. Caxias do Sul: Edipucrs/Educs; 2004. p. 20-36.

12. Sarti CA. A velhice na família atual. Acta Paul Enferm. 2001;14(2):91-6.

13. Caldas CP. Envelhecimento com dependência: responsabilidades e demandas da família. Cad Saúde Pública. 2003;19(3):773-81.

14. Piloto AA, Nunes ATGL, Assis M, Frias SR. O asilo na cidade do Rio de Janeiro. Gerontologia. 1998;6(1):7-12.

15. Goffman E. Manicômios, prisões e conventos. São Paulo: Perspectiva; 1990

16. Davim RMB, Torres GV, Dantas SMM, Lima VM. Estudo com idosos de instituições asilares no município de Natal/RN: características socioeconômicas e de saúde. Rev LatAm Enferm. 2004; 12(3):518-24.

17. Herédia VBM, Casara MB, Cortelletti IA, Ramalho MH, Sassi A, Borges MN. A realidade do idoso institucionalizado. Textos Envelhecimento [periódico na Internet]. 2004[citado 2005 mar. 12];7(2): [cerca de 10 p.]. Disponível em: http://www.unati.uerj.br/tse/ scielo.php?script $=$ sci_arttext\&pid $=\mathrm{S} 1517-59282004000$ $200002 \& \operatorname{lng}=$ pt\&nrm $=\overline{\text { iso }}$ 